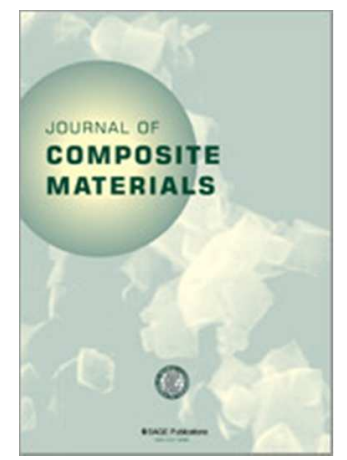

\title{
Effects of water immersion ageing on the mechanical properties of flax and jute fibre biocomposites evaluated by nanoindentation and flexural testing
}

\begin{tabular}{|r|l|}
\hline Journal: & Journal of Composite Materials \\
\hline Manuscript ID: & JCM-12-0602.R2 \\
\hline Manuscript Type: & Original Manuscript \\
\hline Date Submitted by the Author: & 25-Mar-2013 \\
\hline Complete List of Authors: & $\begin{array}{l}\text { Dhakal, Hom Nath; University of Portsmouth, } \\
\text { Zhang, Zhongyi; University of Portsmouth, Engineering } \\
\text { Bennett, Nick; University of Portsmouth, Engineering } \\
\text { Arraiza, Alberto; University of the Basque Country, Nautical and Marine } \\
\text { Machine } \\
\text { López-Arraiza, Alberto; IDEKO SCoop., Composites Laboratory }\end{array}$ \\
\hline Biocomposites, natural fibre composites, mechanical properties, flexural \\
properties, hand lay-up method, water absorption
\end{tabular}




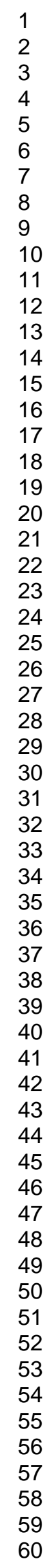

SCHOLARONE ${ }^{m}$

Manuscripts

10

11

12

(3)

16

17

18

20

21

23

24

26

27

29

30

32

33

34

35

36

39

40

41

42

44

45

46

47

48

49

50

52

53

54

56

57

58

60

http://mc.manuscriptcentral.com/jcm 


\section{Figure captions}

Figure 1: Schematic view of a nanoindnetation testing set up

Figure 2: Typical loading/unloading curve

Figure 3: Water absorption curves for different samples

Figure 4: Loading/unloading curves for different dry samples

Figure 5: Loading/unloading curves for wet samples

Figure 6: Load vs. Deformation curves for different samples

Figure 7: SEM images of tension side of dry (a) and wet (b) flexural sample

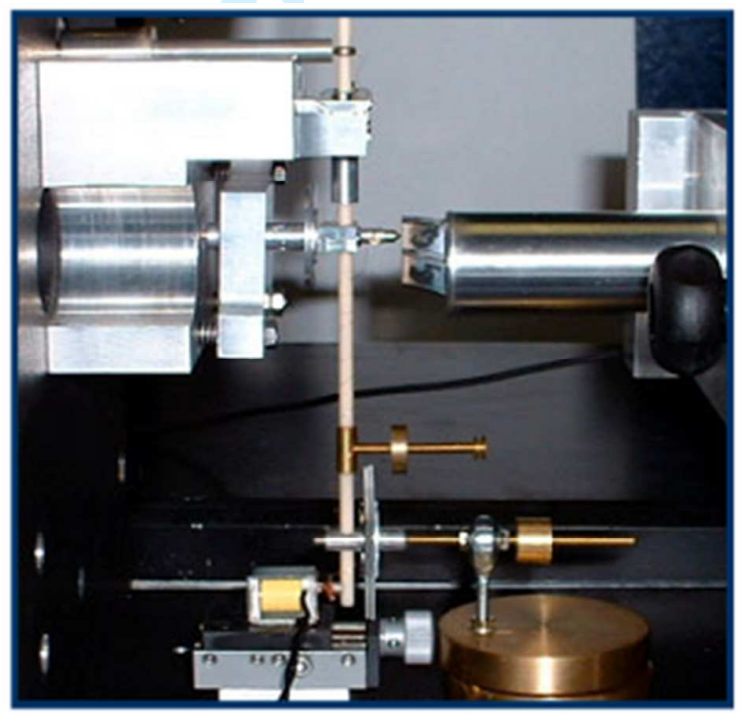

Figure 1: Schematic view of a nanoindnetation testing set up 


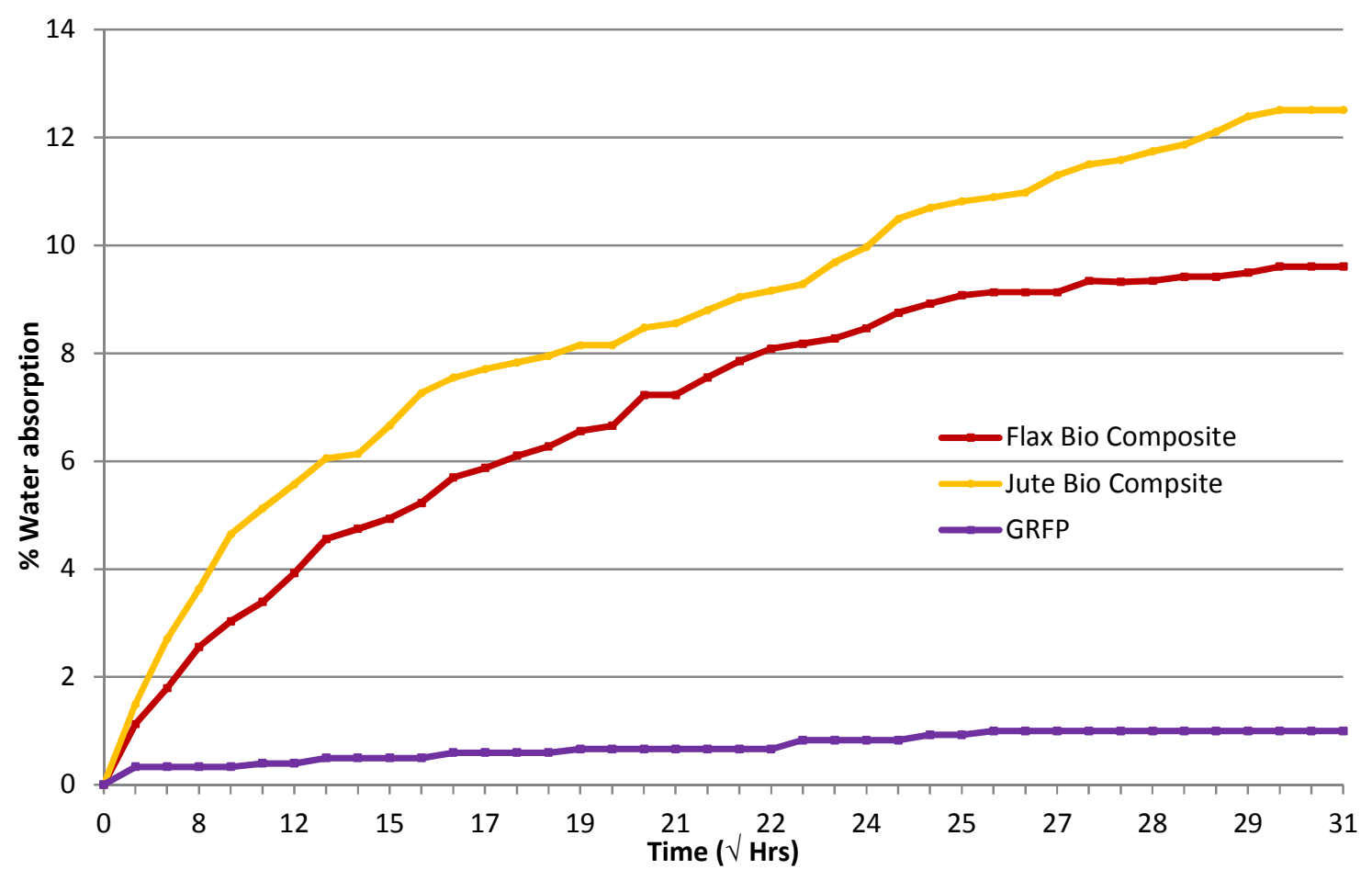

Figure 3: Water absorption curves for different samples 


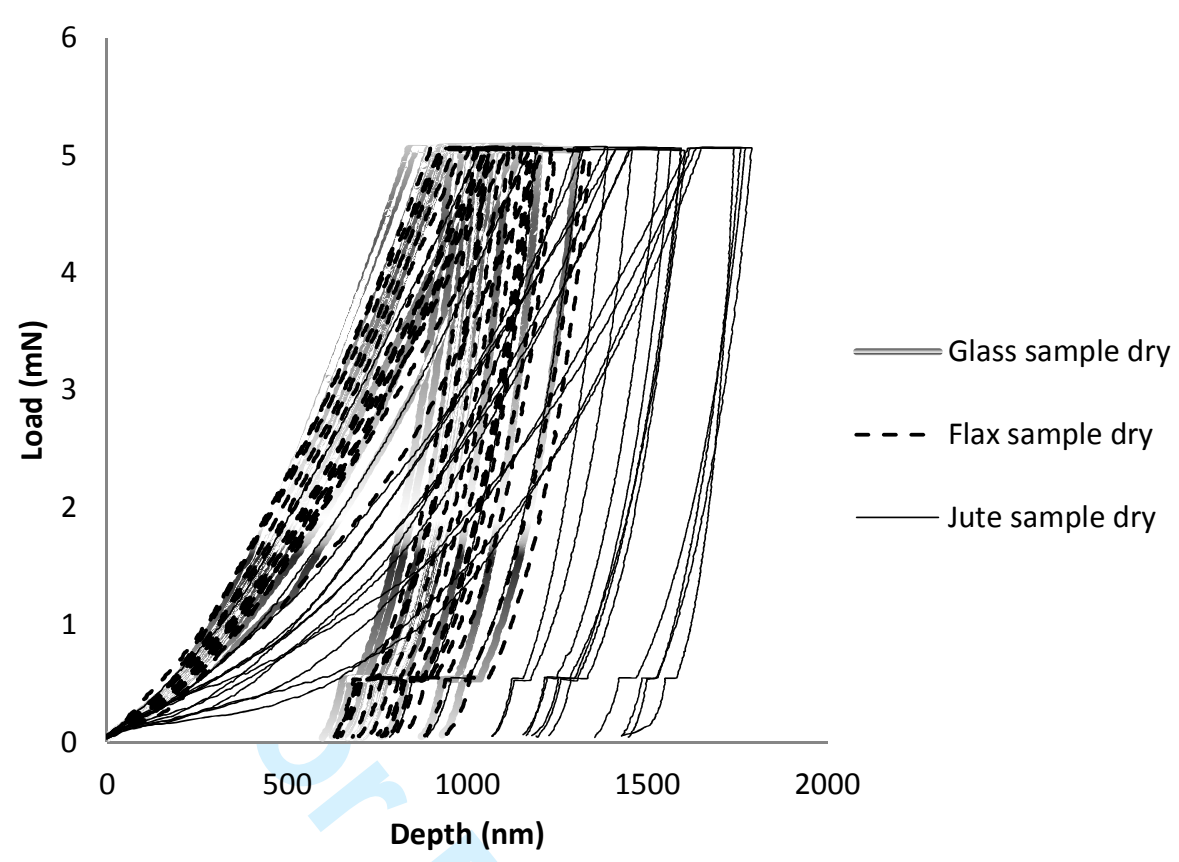

Figure 4: Loading/unloading curves for different dry samples

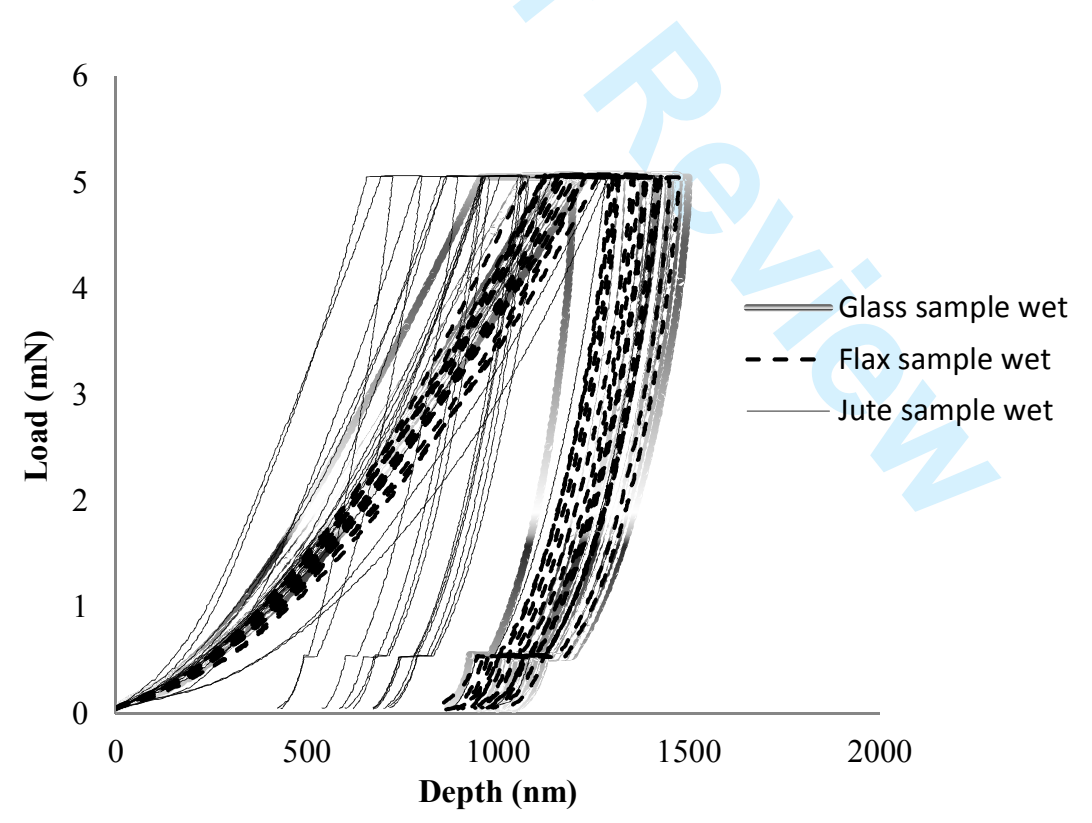

Figure 5: Loading/unloading curves for wet samples 

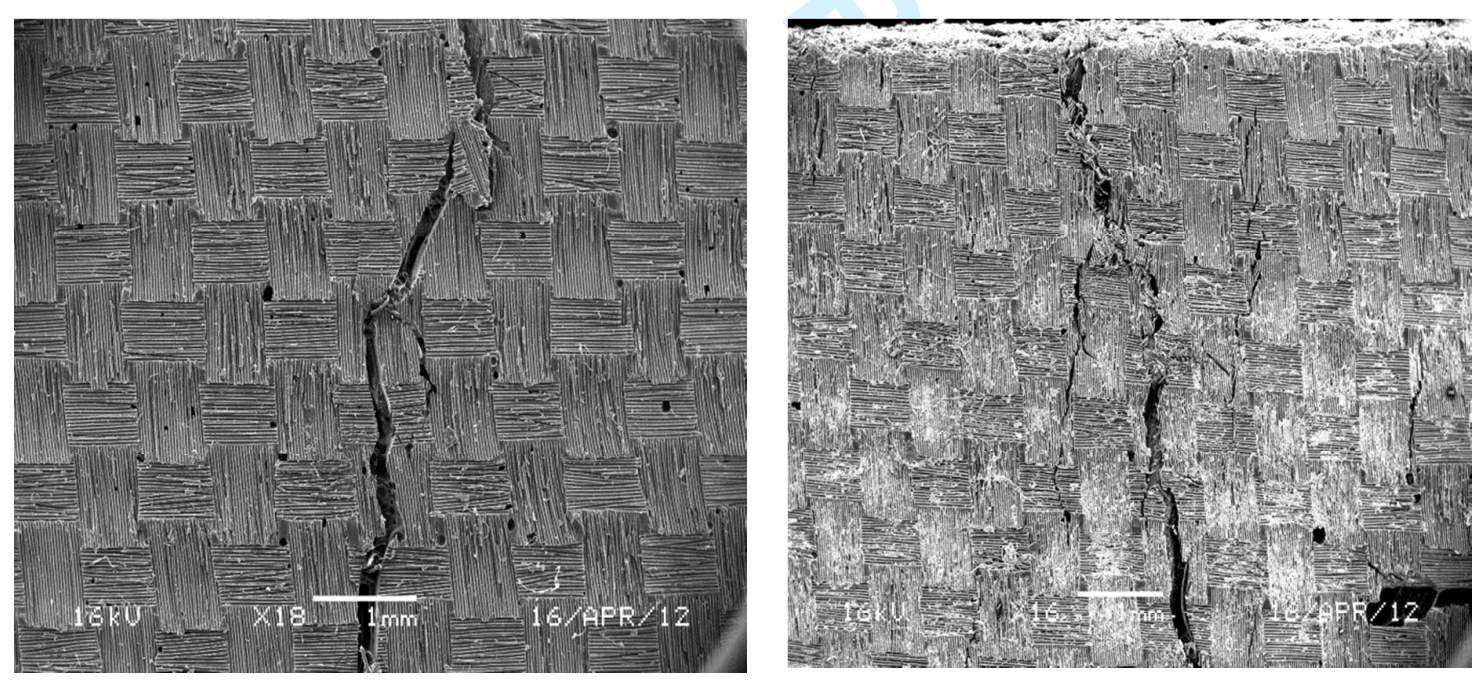

Figure 7: SEM images of tension side of dry (a) and wet (b) 


\title{
Effects of water immersion ageing on the mechanical properties of flax and jute fibre biocomposites evaluated by nanoindentation and flexural testing
}

\author{
H. N. Dhakal ${ }^{\text {aa }}$, Z. Y. Zhang ${ }^{a}$, N. Bennett ${ }^{a}$ A. Lopez-Arraiza ${ }^{\text {b }}$, F.J. Vallejo ${ }^{\text {c }}$ \\ ${ }^{a}$ Advanced Polymer and Composites (APC) Research Group \\ School of Engineering \\ University of Portsmouth, Anglesea Road, Anglesea Building, Portsmouth, Hampshire, PO1 3DJ, \\ U.K. \\ ${ }^{b}$ University of the Basque Country (UPV/EHU) Higher Tech. School of Nautical and Marine \\ Machines Maria Diaz de Haro, 68 - E48920 Portugalete-Bizkaia (Spain).
}

${ }^{c}$ IDEKO-IK4 Research Alliance, Arriaga industrialdea, 2, E-20870 Elgoibar (Gipuzkoa), Spain.

\begin{abstract}
Flax and jute fibres are inexpensive and easily available bast fibres and they are extensively used as reinforcement in polymer matrix composites. However, due to their susceptibility to moisture absorption, their application is restricted to non-structural interior products. In this study, flax and jute fibre reinforced bioresin based epoxy biocomposites were fabricated using hand lay-up method and their nanoindentation and flexural properties were investigated. In order to study the effects of water absorption on the nanoindentation and flexural properties, the biocomposites were subjected to water immersion tests by immersing specimens in a de-ionised water bath at $25^{\circ} \mathrm{C}$ for a period of 961 hours. The nanoindentation behaviour and flexural properties of water immersed specimens were evaluated and compared alongside with dry specimens. The percentage of moisture uptake and diffusion coefficient $(D)$ was recorded higher for jute reinforced specimens compared to flax. The flexural properties for both types of specimens were found to decrease with increase in percentage moisture uptake. Comparison of flexural strength and flexural modulus between flax dry and flax wet biocomposites showed that wet samples lost almost $40 \%$ of its strength and $69 \%$ of its modulus respectively, compared to dry flax samples. The jute wet samples lost $60 \%$ of its strength and $80 \%$ of its modulus, respectively, compared to dry samples. The nanohardness value decreased from $0.207 \mathrm{GPa}$ to $0.135 \mathrm{GPa}$ for dry flax sample after immersion in water.
\end{abstract}

Keywords: Biocomposites; natural fibre composites; mechanical properties; flexural properties hand lay-up method, water absorption.

\footnotetext{
* Corresponding author Tel: + 44 (0) 239284 2582; fax: + 44 (0) 2392842351.

E-mail: hom.dhakal@port.ac.uk (H.N. Dhakal).
} 


\section{1 - Introduction}

In the last decade, the use of natural plant fibres as reinforcement in polymer composites for-

Formatted: Justified making low cost engineering materials has attracted considerable interest. Growing consumer pressure as well as strict environmental legislation has forced manufacturing industries to search for new environmentally compatible materials that can substitute for conventional non-renewable reinforcing materials such as glass fibre [1-5]. The advantages of natural plant fibres over traditional glass fibres are high specific properties, low cost, low density, non abrasion during processing, enhanced energy recovery, reduced dermal and respiratory irritation and good biodegradability $[6,7]$. However, natural fibre reinforced composites and biocomposites are more vulnerable to moisture absorption because of the hydrophilic nature of natural fibres resulting in low moisture resistance behaviour. The hydrophilic problem may be further complicated when natural fibre composites are immersed in water then dried, water uptake and weight loss cause residual stresses and microcracks, which leads to a permanent damage resulting in a poor performance and final failure $[8,9]$.

Hygrothermal effects are confirmed by many authors and show that the diffusion of water into the composites can cause swelling, plasticization, and hydrolysis, profoundly affecting the physical, mechanical and thermal properties as a result of weaker interfacial bonding between fibres and matrix $[10,11]$. Chow and Li [12] studied the effect of moisture absorption on the mechanical properties of sisal-fibre-reinforced polypropylene composites. They reported that water absorption significantly weakened the fibre matrix interface. The effect of water immersion on mechanical properties of hemp fibre reinforced unsaturated polyester composites at room temperature and elevated temperatures were investigated by Dhakal et al. [13]. The report suggests that moisture absorption causes reduction in both tensile and flexural properties.

Thus, in order to use natural fibre composites and biocomposites in structural applications, it is necessary to develop a comprehensive understanding of the mechanisms of ageing and environmental exposure, and their effect on various properties. 
Nanoindentation has become a popular way of measuring the mechanical properties of materials at smaller length and load scales than allowed by other methods [14-17]. More recently, Aldousiri et al [18] used this technique to investigate the hardness and modulus of spent PA-12 and its nanocomposites with varying concentrations of clay loading. Bourmaud and Baley [19], for example, studied the effect of process parameters on the mechanical and thermal behaviour of flax fibre biocomposites using thermogravimetric analysis (TGA) measurements and nanoindentation testing. They concluded in their report that the nanoindentation technique is an appropriate technique for comparison of modulus and hardness properties of vegetable fibre composites. However, there are hardly any reported works on the detection of water absorption damage on the nanomechanical and flexural properties of flax and jute fibre reinforced biocomposite materials.

$\mid$

This study aims at investigating the effect of water immersion ageing on the nanomechanical and mechanical properties of two commonly used flax and jute reinforced biocomposites. The investigated nanomechanical properties include nanohardness and elastic modulus and mechanical properties include flexural strength and modulus.

\section{2 - Materials and Experimental Procedure}

The matrix material used in this study was Super Sap TM 100/1000 (Entropy Resins, Inc.)+ Formatted: Justified of which $55 \%$ is made from waste streams of other industrial processes, such as wood pulp and bio fuels production. The mixing ratio of the 1000 Hardener was 100:48 by weight.

The jute fibre reinforcement was supplied by Tejijut Company as a balanced 0/90 plain weave fabric of $305 \mathrm{~g} / \mathrm{m}^{2}$ in weight. The flax fibre reinforcement was FLAXPLY® supplied by Lineo Company as a balanced fabric $0 / 90$ of $200 \mathrm{~g} / \mathrm{m}^{2}$ in weight. The laminates were manufactured by hand lay-up and vacuum bagging process in plates of $3 \mathrm{~mm}$ thick consisting of 5 jute plies for jute and 8 flax plies for flax laminates, respectively. The different plies were used in jute and flax to make it similar weight fraction so that they can be compared. Total fiber weight fraction was $41 \%$ and the void content was $4.6 \%$ for both samples. The void content was calculated according to 
ASTM D2734-94 and the percentage in weight was calculated by means of weighing the fiber used and the final biocomposite plate.

\section{1 - Water absorption test}

The water absorption behaviour of flax and jute fibres reinforced epoxy based-

Formatted: Justified biocomposites was investigated in accordance with BS EN ISO 62:1999 [20]. First, all the specimens were dried in an oven at $100^{\circ} \mathrm{C}$ and then were allowed to cool to room temperature in a desiccator before weighing them to the nearest $0.1 \mathrm{mg}$. This process was repeated until the mass of the specimens were reached constant. Water absorption tests were conducted by immersing the specimens in a de-ionised water bath for 961 hours. The moisture absorption (moisture content) was calculated by the weight difference.

\section{2 - Nanoindentation testing}

For the nanoindentation specimens, small coupons were cut from the composite laminates+ Formatted: Justified with square geometry of $18 \mathrm{~mm}$ side and thickness approximately $3 \pm 0.1 \mathrm{~mm}$. A suitable adhesive was used to fix them onto the nanoindentation apparatus. The tests were carried out using Nano Test $^{\mathrm{TM}}$ equipment from Micro Materials U.K. as shown in Figure 1. A (three sided pyramid) Berkovich diamond indenter tip was used to measure the nanohardness properties. All tests were conducted at room temperature. Sixteen symmetrical indentations (in the form of a 4 x 4 matrix, 30 $\mu \mathrm{m}$ apart) were made in each specimen. All the testing was programmed in such a way that the indenter came into contact with the sample surface and load increased at a constant rate of $2 \mathrm{mN} / \mathrm{s}$ until the load reached the maximum load, $P_{\max }$ of $5 \mathrm{mN}$. Then the load was held at its maximum load for $60 \mathrm{~s}$ before unloading at same constant rate.

A schematic representation of a typical loading-depth curve obtained during a one full cycle of loading and unloading is presented in Figure 2. As a load is applied to an indenter in contact with a specimen surface, an indent/impression is made which consists of plastic and elastic deformation. Recovery of elastic deformation occurs at the start of unloading. The important quantities in this loading-unloading cycle are maximum load $\left(\mathrm{P}_{\max }\right)$, the maximum depth $\left(\mathrm{h}_{\max }\right)$, the final depth after 
unloading $\left(\mathrm{h}_{\mathrm{r}}\right)$ and the slope of the upper portion of the unloading curve, $\mathrm{S}$, known as the elastic contact stiffness. The hardness and elastic modulus can be derived by the most widely used method developed by Oliver and Pharr [21].

\section{3 - Flexural testing}

The flexural strength and modulus of flax and jute biocomposites were performed using a Formatted: Justified

Zwick/Roell Z030 universal testing machine supplied by Zwick in a three-point bending mode

Formatted: Highlight using a cross head speed of $2 \mathrm{~mm} / \mathrm{min}$. The three point bending test specimens were $70 \mathrm{~mm}$ long, $15 \mathrm{~mm}$ width and $3 \mathrm{~mm}$ thick.

\section{4 - Scanning Electron Microscopy}

The tension surfaces of the fractured specimens subjected to flexural testing were examined using a scanning electron microscope (SEM) JEOL JSM 6100, supplied by JEOL (UK) Ltd. After

Formatted: Justified

Formatted: Highlight adhering to SEM stubs, a thin layer of gold/palladium was applied to the specimens prior to SEM examination.

\section{3 - Results and Discussion}

\section{1- Moisture absorption behaviour}

The percentage of water absorption in the biocomposite samples was calculated by weight

Formatted: Justified difference between the samples immersed in water and the dry samples using the equation (1).

$$
\Delta M(t)=\frac{M_{t}-M_{o}}{M_{o}} \times 100
$$

where $\Delta M(t)$ is moisture uptake, $M_{o}$ and $M_{t}$ are the mass of the specimen before and during aging, respectively.

The coefficient of diffusion $(D)$ defined as the slope of the normalised mass uptake against* 
Where, $k$ is the initial slope of a plot of $M(t)$ versus $t^{1 / 2}, M_{m}$ is the maximum weight gain and $h$ is the thickness of the composites.

Figure 3 shows percentage of weight gain as a function of square root of time for flax and jute samples immersed in de-ionised water at room temperature $\left(23{ }^{\circ} \mathrm{C}\right)$. The maximum percentage weight gain for flax, jute and glass fibre composite immersed at room temperature for 961 hours is 9.61, 14.41 and $0.99 \%$, respectively. The water uptake process for both flax and jute biocomposites is linear in the beginning, then slows and approaches saturation after prolonged time, following a Fickian diffusion process. As it can be seen in Figure 3, both the initial rate of water absorption and the maximum water uptake increases for flax and jute bicomposites as the immersion time increases. Moisture diffusion in polymeric composites has shown to be governed by three different mechanisms similar to polymeric matrix materials $[22,13]$.

1. The first involves diffusion of water molecules inside the micro gaps between polymer chains.

2. The second involves capillary transport into the gaps and flaws at the interfaces between fibre and the matrix.

3. The third involves transport of micro-cracks in the matrix arising from the swelling of fibres (particularly in the case of natural fibre bicomposites such as flax and jute).

Table 1 presents the diffusion coefficients for both biocomposite specimens. It can be seen+ from Figure 3 and Table 1 that the maximum moisture content and the diffusion coefficient values increases steadily with an increase in immersion time up to saturation. The increase is more pronounced for the jute specimens than flax showing jute fibre bicomposite absorbing water at greater rate than that of flax. The major constituents of mature unprocessed jute fibre are cellulose (61-71.5 wt.\%), hemicelluloses (13.6-20.4 wt.\%) lignin (12-13 wt.\%) and pectin (0.2 wt.\%). The constituent of flax fibre is cellulose (71 wt.\%), hemicelluloses (18.6-20.6 wt.\%), while other components are lignin $(2.2 \mathrm{wt. \%})$ and pectin $(2.3 \mathrm{wt} . \%)$. As hemicelluloses are a very hydrophilic
Formatted: Justified

Formatted: Highlight 
polymer, it is largely responsible for the water absorption behaviour exhibited by plant fibres [23, 24]. With higher percentage of cellulose and hemicelluloses content of flax fibre, one would have expected flax composite to have higher moisture content than that of jute fibre composites. However, the jute fibre reinforced biocomposite samples show higher water absorption than that of flax samples. The disparity in water absorption between jute and flax composites in this study can be attributed due to some other factors such as weaker fibre matrix adhesion for jute biocomposites compared to flax, hence promotes higher moisture content. As the natural fibres exhibit hydrophilic behaviour in their natural environment, this would explain the increased rate of water absorption compared with that of glass fibre as seen in the Diffusion co-efficient in Table 1.

\section{2- Effect of moisture absorption on nanomechanical and flexural properties}

\subsubsection{Nanomechanical properties}

The average load versus indentation depth for all tested samples in dry and wet conditions is shown in Figures 4 and 5 . The average values of experimental results extracted from the loadingunloading curves are presented in Table 2. It can be seen from figures 4 and 5 that there are significant differences in terms of slope of the curves and depth for the sample with and without water absorption.

For flax reinforced biocomposite specimens, nanoindentation test results show that as the water absorption increases, the hardness and the elastic modulus decreases. The nanohardness value for the flax dry sample is $0.207 \mathrm{GPa}$, whereas for the wet sample, the hardness decreases from $0.207 \mathrm{GPa}$ to $0.135 \mathrm{GPa}$ (an approximately $35 \%$ decrease). Similarly, the reduced modulus of flax dry sample is reduced from 4.483 MPa to $3.963 \mathrm{MPa}$ (an approximately $11.6 \%$ decrease) as a result of moisture ingress. The decrease in nanohardness and reduced modulus of the flax sample is associated with the weak interface between the matrix and the reinforcement as a result of water absorption. The hardness value for jute dry specimen is $0.107 \mathrm{GPa}$, whereas the hardness value for jute wet sample increases to $0.112 \mathrm{GPa}$ (an increase of 5\%). For jute sample, it does not seem like 
water absorption has had any adverse effect on hardness value. However, there is decrease in reduced modulus for jute wet sample, from 3.687 to $3.331 \mathrm{MPa}$ (decrease of 9.7\%) as a result of water absorption.

The deformation depth increases for water immersed specimens compared to the dry ones. This phenomenon can be explained by considering the water uptake characteristics of flax and jute biocomposites as follows: As the immersion time increases, the moisture uptake also increases due to the hydrophilic nature of these fibres which eventually lead to the formation of a weak fibre matrix interface. When the water uptake reaches its saturation level, the bound water and free water stays as a reservoir in the composite. This leads to softening of the fibres and weakening of the fibre matrix adhesion resulting in reduced material properties. When the indentation probe reaches these soft fibres and weakened interfaces, the deformation becomes higher and the hardness gets reduced.

\subsubsection{Flexural properties}

The load vs. deformation curves for flax and jute biocomposite specimens are shown int

Figure 6. Average values for the flexural results calculated from the load vs. deformation traces of five specimens tested in the flexural testing for flax and jute biocomposite samples are presented in Table 3. The flexural strength and modulus drop significantly for both flax and jute samples after the water immersion. The decrease in flexural properties after water immersion can be related to the weak fibre-matrix interface due to water absorption. Jute fibre reinforced wet specimen displayed the highest reduction in flexural strength and modulus values, a decrease of 60.4 and $80.0 \%$, respectively, compared with the dry jute sample. This reduction can be explained as excessive water absorption by the wet jute sample leads to an increase in the absorbed bound water and a decrease in free water. Another reason for the reduction of strength and modulus for wet samples can be explained by the weakening of the cellulose structures of natural fibres by the water molecules in the cellulose network structure in which water acts as a plasticiser and it permits cellulose molecules to move freely. Consequently the mass of the cellulose is softened and can change the dimensions of the fibre easily with the application of forces [25]. 
The flexural test results show that of all the flexural properties investigated, the flexural modulus was affected most by water absorption as seen in Table 3 . The flexural modulus decreases for both flax and jute reinforced samples. The reduction in flexural modulus for flax and jute reinforced specimens compared to dry specimens is approximately 69.2 and $80.0 \%$, respectively. A plausible explanation for this would be that, the elastic modulus is a fibre-sensitive property in composites and is affected as a result of moisture absorption. This effect can be particularly greater for the composites with higher fibre and void content, in which stress transfer capability between fibre and matrix interface gets sharply reduced due to moisture content.

The failure flexural deformation value for all water-immersed specimens was found to increase compared to dry specimens. The increase in elongation upon exposure of the samples to a wet environment can be attributed to the plasticization of natural fibre biocomposite samples caused by moisture absorption.

\subsection{Failure mechanisms}

Figure 7 (a) and (b) shows a Scanning Electron Microscope (SEM) images of dry and wet

Formatted: Justified flax biocomposites. As seen in the SEM images in Figure 7 image (a) shows the failure of a dry specimen exhibiting a definitive fracture line due to the tension created under the 3 point bending test. The fracture in image (a) in comparison with image (b) shows a clean brittle fracture whereas (b) shows a ductile fracture with numerous other secondary cracks forming as well as the main fracture line. These smaller secondary cracks show the effects of the water absorption and are likely to be the result of de-bonding as well as delamination between the fibre reinforcement and the matrix itself. This would explain the lower mechanical performance of the wet samples compared with the dry. Increased ductility shown in image (b) would explain the increased deformation of the wet samples. This ultimately results in a loss of stiffness and rigidity which would explain the lower peak loads and flexural strength in the samples subjected to water absorption compared with the dry samples. 


\section{4 - Conclusions}

Water absorption behaviour and the effect of water absorption on the nanohardness and the flexural properties of woven fabric flax and jute fibre reinforced bioresin based epoxy biocomposites have been studied following immersion at room temperature with the application of nanoindentation and flexural testing. Under the current test conditions, both biocomposites followed the fickian diffusion behaviour, where the moisture uptake percentage increases linearly with square root of time and gradually levels off after the saturation level is reached. The nanohardness value for the flax dry sample is $0.207 \mathrm{GPa}$, whereas for the wet sample, the hardness decreases from $0.207 \mathrm{GPa}$ to $0.135 \mathrm{GPa}$ (an approximately $35 \%$ decrease). Similarly, the reduced modulus of flax dry sample is reduced from 4.483 MPa to $3.963 \mathrm{MPa}$ (an approximately $11.6 \%$ decrease) after exposure to water. The decrease in nanohardness and reduced modulus properties of water immersed specimen is associated with the weak fibre interface as a result of water absorption. Similarly, the water absorption had negative effect on flexural properties. The reduction in flexural strength for flax and jute reinforced specimens compared to dry specimens is approximately 40 and $60 \%$, respectively. Similarly, the reduction in flexural modulus for flax and juts specimens compared to dry specimens is approximately 69 and $80 \%$, respectively. A plausible explanation for this would be that, the strength and elastic modulus is a fibre-sensitive property in composites and is affected as a result of moisture absorption.

\section{Acknowledgements:}

"This research received no specific grant from any funding agency in the public, commercial, or not-profit sectors."

\section{References}

1. Faruk, O., Bledzki, A.K., Fink., H.P., and Sain, M. (2012). Biocomposites reinforced with naturalfibres: 2000-2010, Progr Polym Sci.; d.o.i./10.1016/j.progpolymsci.2012.04.003. 
2. Bledzki A.K. and, Gassan J. (1999). Composites reinforced with cellulose based fibers, Progr Polym Sci.; 24(2): 221-74.

3. Behzad T. and Sain M. (2007). Finite element modeling of polymer curing in natural fiber reinforced composites. Compos Sci Technol.; 67(7/8): 1666-73.

4. Dhakal H.N., Zhang Z.Y. and Richardson M.O.W. (2009). Creep behaviour of natural fibre reinforced unsaturated polyester composites, Journal of Biobased Materials Bioenergy, 2009, (3), 1-6.

5. Bolton J (1995). The potential of plant fibres as crops for industrial use. Outlook Agric; 24: 85-9.

6. Shahzad, A. (2012). Hemp fibre and its composites-a review, J. Comp. Mater., 46:973-986.

7. Dhakal, H.N., Zhang, Z.Y, and Richardson, M.O.W, and Errajhi, O.A.Z. (2007). The low velocity impact response of non-woven hemp fibre reinforced unsaturated polyester composites. Comp. Struct. ; 81(4): 559-67.

8. Panthapulakkal, S. and Sain, M. (2007). Studies on the water absorption properties of short hemp-glass fibre hybrid polypropylene composites. J. Comp. Mater; 41:1871-1883.

9. Thwe, M.M. and Liao, K. (2002). Effects of environmental aging on the mechanical properties of bamboo-glass fiber reinforced polymer matrix hybrid composites. Comp. Part A; 33: 43-52.

10. Gassan, J, and Bledzki, A.K. (1997). Effect of moisture content on the properties of silanized jute-epoxy composites. Polym. Comp; 18(2): 179-84.

11. Chen, H., Miao, M. and Ding, X. (2011). Chemical treatments of bamboo to modify its moisture absorption and adhesion to vinyl ester resin in humid environment. J. Comp. Mater. 45:15331512

12. Chow, C.P.L, Xing, X.S, Li, R.K.Y., Xing, X.S, and Li, R.K.Y. (2007). Moisture absorption studies of sisal fibre reinforced polypropylene composites. Comp. Sci. Technol.; 67(2): 306-13.

13. Dhakal, H.N., Zhang Z.Y. and Richardson M.O.W. (2007). Effect of water absorption on the mechanical properties of hemp fibre reinforced unsaturated polyester composites. Comp. Sci. Technol.; 67(7/8): 1674-83. 
14. Gregory, J.R., and Spearing, S.M. (2005). Nanoindentation of neat and in situ polymers in polymer-matrix composites. Comp. Sci. Technol., 65:595-607.

15. Randall, N.X., and Harris, A. (2000). Nanoindentation as a tool for characterising the mechanical properties of tribological transfer films. Wear; 245(1/2): 196-203.

16. Farrissey, L.M., and McHugh, P.E. (2005). Determination of elastic and plastic material properties using indentation: Development of method and application to a thin surface coating. Mat Sci Eng-A-Struct 2005; 399: 254-66.

17. Dhakal, H.N., Zhang, Z.Y. and Richardson, M.O.W. (2006). Nanoindentation behaviour of layered silicate reinforced unsaturated polyester nanocomposites. Polym. Test.; 25: 846-52.

18. Aldousiri, B., Dhakal, H. N., Onuh, S., Zhang, Z. Y., and Bennett, N. (2011). Nanoindentation behaviour of layered silicate filled spent polyamide-12 nanocomposites. Polym. Test., 30:688692.

19. Bourmaud, A., and Baley, C. (2010). Effects of thermo mechanical processing on the mechanical properties of biocomposite flax fibers evaluated by nanoindentation. Polym. Deg. Stab. 95:1488-1494.

20. Plastics - determination of water absorption, BS EN ISO 1999; 62:1.

21. Oliver, W.C., and Pharr, G.M. (1992). An improved technique for determining hardness and elastic modulus using load and displacement sensing indentation experiments, J Mater Res ; 7(6): 1564-83.

22. Espert, A., Vilaplana, F. and Karlsson, S. (2004). Comparison of water absorption in natural cellulosic fibres from wood and one year crops in polypropylene composites and its influence on their mechanical properties, Comp. Part A. 35:1267-1276.

23. Mohanty, A.K., Misra, M., \& Hinrichsen, G. (2000). Biofibres, biodegradable polymers and

Formatted: Highlight biocomposites: An overview. Macromolecular Materials and Engineering, 276-277(1), 1-24.

24. Fakirov, S., and Bhattacharya, D. (2007). Engineering Biopolymers:Homopolymers, Blends and Composites. Auckland, New Zealand: Hanser Gardner Publications. 
1

2

3

4

5

6

7

8

9

10

11

12

13

14

15

16

17

18

19

20

21

22

23

24

25

26

27

28

29

30

31

32

33

34

35

36

37

38

39

40

41

42

43

44

45

46

47

48

49

50

51

52

53

54

55

56

57

58

59

60
25. Tajvidi, M. and Ebrahimi, G. (2003). Water uptake and mechanical characteristics of natural fibre polypropylene composites, J. Appl. Polym. Sci., 88:941-946. 
2

3

4

5

6

7

8

9

10

Table 1: Moisture uptake of flax and jute biocomposites immersed in water at room temperature

\begin{tabular}{|c|c|c|c|}
\hline Samples & $\begin{array}{l}\text { Saturation moisture uptake } \\
\qquad \mathrm{M}_{\mathrm{m}}(\%)\end{array}$ & $\begin{array}{l}\text { Initial slope of plot } \\
\qquad(\mathrm{k}) \\
M(t) \text { versus } \mathrm{t}^{1 / 2}\end{array}$ & $\begin{array}{l}\text { Diffusion coefficient, } \\
\qquad \mathrm{D}, \times 10^{-3}\left(\mathrm{~m}^{2} / \mathrm{s}\right)\end{array}$ \\
\hline Flax biocomposite & $9.61 \quad 020$ & 0.303 & 3.71 \\
\hline Jute biocomposite & 14.41 & 0.464 & 4.12 \\
\hline Glass reinforced plastic & 0.99 & 0.033 & 0.70 \\
\hline Glass fibre data & d for reference. Data in & are means with a & ple size of 4 for each \\
\hline
\end{tabular}


Table 2: Nanoindentation results for different samples

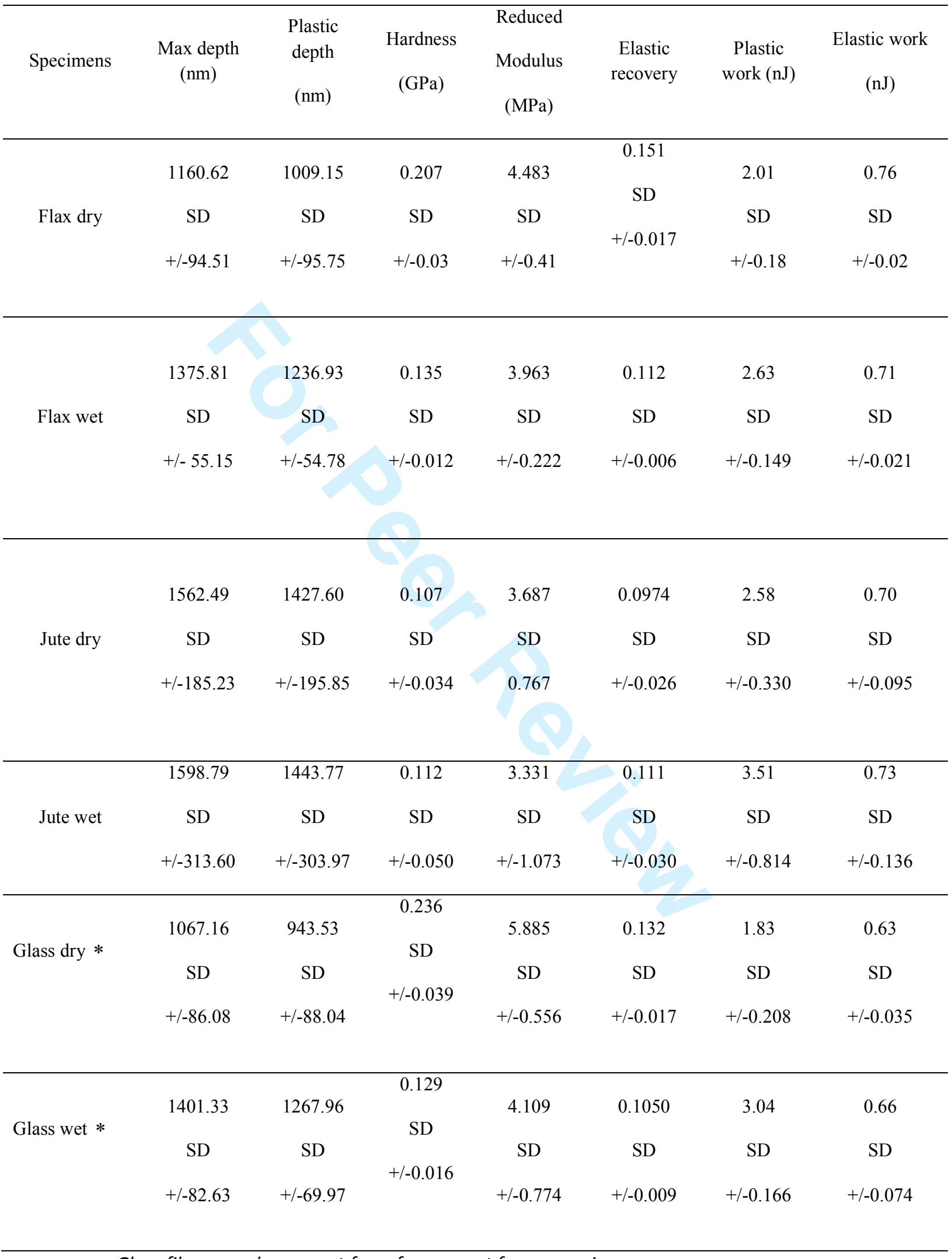

* Glass fibre samples are put for reference not for comparison.

http://mc.manuscriptcentral.com/jcm 
1

2

3

4

5

6

7

8

9

10

11

12

13

14

15

16

17

18

19

20

21

22

23

24

25

26

27

28

29

30

31

32

33

34

35

36

37

38

39

40

41

42

43

44

45

46

47

48

49

50

51

52

53

54

55

56

57

58

59

60

Table 3: Flexural strength and modulus for dry and wet biocomposite samples

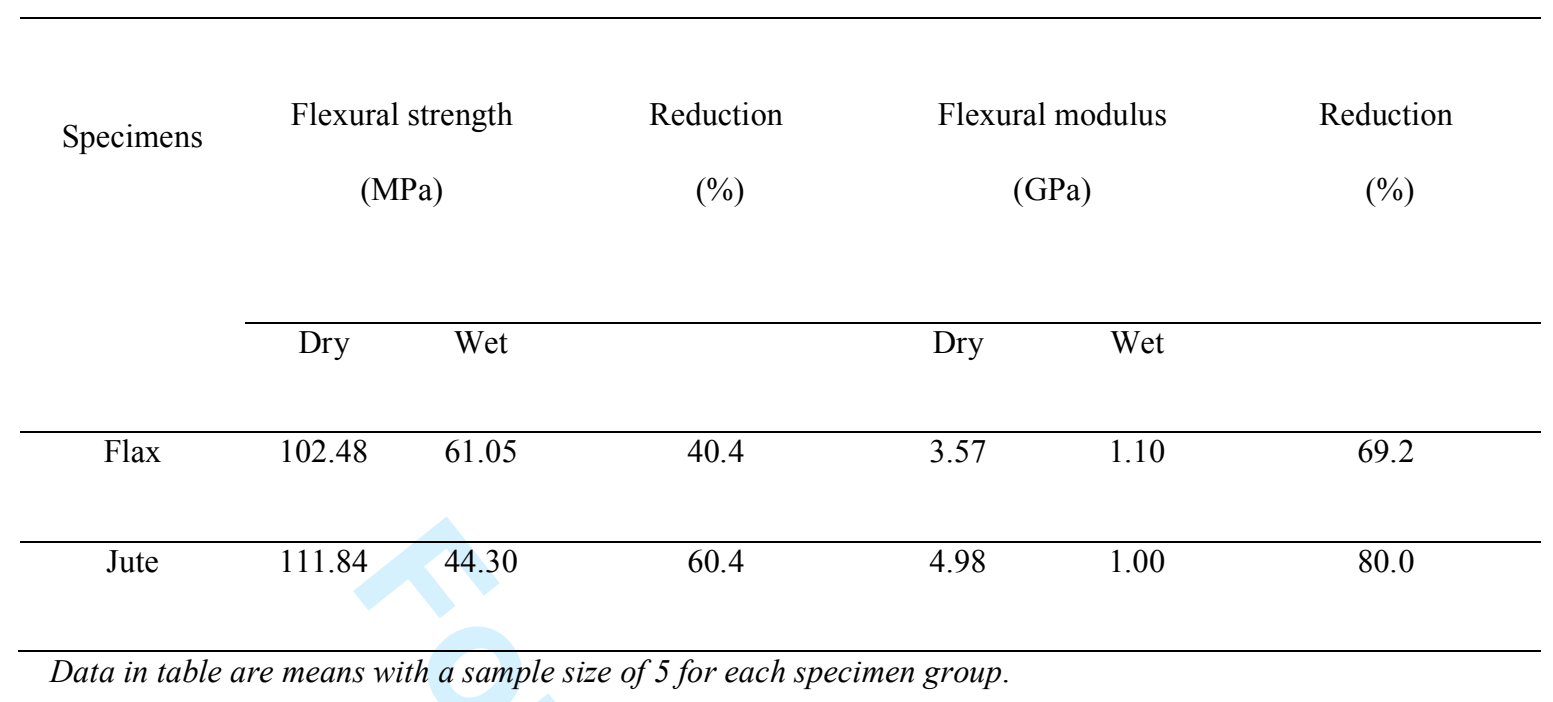

